\title{
New therapeutic avenues in ulcerative colitis: thinking out of the box
}

\author{
Joana Torres, ${ }^{1}$ Silvio Danese, ${ }^{2}$ Jean-Frédéric Colombel ${ }^{3}$
}

${ }^{1}$ Gastroenterology Service, Surgery Department, Hospital Beatriz Ângelo, Loures, Portugal

${ }^{2}$ Department of Gastroenterology, IBD Center, Humanitas Clinical and Research Center, Milan, Italy ${ }^{3}$ The Dr Henry D Janowitz Division of Gastroenterology, Icahn School of Medicine at Mount Sinai New York, New York, USA

\section{Correspondence to} Professor Jean-Frédéric Colombel, The Dr Henry D Janowitz Division of Gastroenterology, Icahn School of Medicine at Mount Sinai, 1 Gustave Levy Place, New York, NY 10029, USA; jean-frederic.colombel@mssm. edu

Received 24 January 2013 Revised 15 March 2013 Accepted 20 March 2013
To cite: Torres J, Danese $S$, Colombel J-F. Gut 2013;62:1642-1652.

\section{ABSTRACT}

Ulcerative colitis (UC) is a chronic idiopathic inflammatory disease of the gastrointestinal tract that affects the mucosal lining of the colon. Recent epidemiological data show that its incidence and prevalence are increasing in many parts of the world, in parallel with altered lifestyles, improved access to health, improved sanitation and industrialisation rates. Current therapeutic strategies for treating UC have only been moderately successful. Despite major recent advances in inflammatory bowel disease therapeutic resources, a considerable proportion of patients are still refractory to conventional treatment. Less than half of all patients achieve long-term remission, many require colectomy, and the disease still has a major impact on patients' lives. Moreover, recent data point to slightly raised mortality. While these outcomes could be partly improved by optimising current therapeutic strategies, they clearly highlight the need to develop new therapies. Currently, a number of promising and innovative therapeutic approaches are being explored, some of which will hopefully survive to reach the clinic. Until such a time arrives, it is important that a better understanding of the clinical particularities of the disease, an improved knowledge of the host-microbiome negative interactions and of the environmental factors beyond disease development is achieved to obtain the final and desired outcome: to provide better treatment and quality of life for patients with this disabling disease.

\section{INTRODUCTION}

Ulcerative colitis (UC) is emerging as an important public health problem. The disease can occur in all parts of the world and in all races, but rates vary widely from industrialised countries to developing nations. Epidemiological studies show that there is a significant increase in the incidence of UC in most regions of the world. ${ }^{1-6}$ Being a chronic lifelong disease with onset at a young age, the prevalence of UC is likely to continue to increase in future decades. This expected increased prevalence will translate into increasing healthcare expenditures. UC has already been associated with greater per patient costs than asthma, hypertension and chronic obstructive pulmonary disease, ${ }^{7}$ so the costs of the disease will become increasingly relevant to the economy as a whole and will become disproportionally high. ${ }^{8}$ Furthermore, recent mortality data reveal that there is still a $10 \%$ increase in intermediate- and long-term mortality among patients with UC, with even higher percentages for patients diagnosed in childhood or adolescence. ${ }^{9}$

Current management strategies in UC typically follow a step-up strategy. ${ }^{10}{ }^{11}$ While this approach can be expected to maintain a considerable proportion of patients in remission, there remains a substantial proportion in whom disease activity will persist over time, ${ }^{12}{ }^{13}$ eventually requiring surgery. ${ }^{12}{ }^{14}$ Whereas some of these outcomes might be improved by optimising current therapeutic strategies, the truth is that they also highlight a major unmet medical need.

Previous years have been marked by landmark discoveries and advancements in our understanding of the components involved in innate and acquired immune responses in UC. These discoveries were paralleled by an exponential increase in the number of new and investigational therapeutic targets. ${ }^{15}$ Unfortunately, many of these strategies-although very auspicious in animal models and preliminary trials-have not performed well in randomised clinical trials and failed to reach the clinics, highlighting the complexity of the disease and the dynamic process of inflammation.

In this paper we will start by briefly discussing some recent and new therapeutic strategies that will probably soon be used in the clinic. Thereafter, and since a recent review on new immunological targets in UC has recently been published in Gut,${ }^{15}$ we have deliberately chosen to focus on two other key components of UC physiopathology that could be used as therapeutic targets in UC-the mucosal barrier and the luminal components. Finally, we will discuss innovative ways for new drug discoveries such as characterisation of plant-derived medicines and computational drug repositioning, and we will debate some clinical and epidemiological observations of the disease that could foster the development of future avenues for translational research.

\section{PROMISING DEVELOPMENT PROGRAMMES IN UC Anti-adhesion strategies}

The recruitment, homing and adhesion of $\mathrm{T}$ lymphocytes from the peripheral circulation to the gut mucosa are crucial steps for maintaining the inflammatory process. Regulating the various steps involved in the migration of leucocytes to the gut using monoclonal antibodies directed against integrins $(\alpha 4, \alpha 2$ and $\beta 7)$, adhesion molecules (MAdCAM-1, VCAM-1 or ICAM-1), chemokine receptors (CCR-9) or chemokines (IP-10) could therefore blunt inflammation and pathological responses in tissues and become an interesting pathway to target for drug development in inflammatory bowel disease (IBD). ${ }^{16}$

The first anti-adhesion agent that proved to be effective in the treatment of IBD was natalizumab, an anti- $\alpha 4$-integrin IgG4 non-gut selective antibody. ${ }^{17}$ The initial enthusiasm surrounding its 
success for induction and maintenance of remission in CD was limited by reports of the aggressive progressive multifocal leucoencephalopathy (PML). Nevertheless, this agent provided proof of concept and paved the way for the development of new anti-adhesion agents such as vedolizumab (VDZ; MNL-0002), aliforcasen, rhuMAb $\beta 7$ and CCR9 inhibitors. ${ }^{17}$ VDZ, an $\alpha 4 \beta 7$ integrin-neutralising monoclonal antibody, is the anti-adhesion molecule next in line to reach the clinic. It is gutspecific and does not affect the peripheral blood cell count, so it has the potential to provide gut-selective immunosuppression with similar or greater efficacy than natalizumab with a lower risk of systemic infection. ${ }^{18}$

The results of the phase III randomised, placebo-controlled, blinded, multicentre study on induction and maintenance of the clinical response and remission with VDZ in UC (ClinicalTrials. gov NCT00783718) have recently been presented. ${ }^{19}{ }^{20}$ In the induction study, 374 patients were randomised to receive VDZ $(n=225)$ or placebo $(n=149)$. At week 6 a significantly greater proportion of the patients treated with VDZ achieved clinical response, remission and mucosal healing compared with placebo-treated patients, with a similar rate of adverse events in both groups. ${ }^{19}$ During the maintenance study, 373 patients who met the response criteria at week 6 were randomised to receive intravenous VDZ $300 \mathrm{mg}$ every 4 weeks $(\mathrm{n}=125)$, every 8 weeks $(n=122)$ or placebo $(n=126)$. Of these patients, $44.8 \%, 41.8 \%$ and $15.9 \%$, respectively, achieved clinical remission and 56\%, 51.6\%, and 19.8\%, respectively, achieved mucosal healing at week $52(\mathrm{p}<0.0001)$. No increase in the rates of opportunistic or enteric infections was observed with VDZ and there were no reported cases of PML. Of note, the population entering the induction and maintenance studies were considered to be a difficult-to-treat population, with $40 \%$ of patients having received prior treatment with anti-tumour necrosis factor (TNF) agents. However, subanalysis by failure of prior treatment with anti-TNF agents, immunomodulators or corticosteroids did not reveal any differences. ${ }^{21}$

\section{JAK inhibitors}

The Janus kinase (JAK) family of tyrosine kinases contains four members: JAK1, JAK2, JAK3 and TYK2. They are responsible for mediating signal transduction for a variety of cytokine receptors including interleukins (ILs) 2, 4, 6, 7, 9, 12, 15 and $21 .{ }^{15}$ Upon ligation of these receptors with their ligand cytokine, JAKs become activated leading to activation of genes relevant to the immune response.

Tofacitinib is a novel oral small-molecule, selective inhibitor of JAK1 and JAK3 and, to a lesser extent, JAK2. It suppresses the differentiation of pathogenic Th1 and Th17 cells as well as innate immune cell signalling. ${ }^{22}$ A phase II study of tofacitinib as an induction therapy in patients with moderately to severely active UC has been conducted and its results recently published. ${ }^{23}$ One hundred and ninety-four patients were randomised to receive tofacitinib $0.5 \mathrm{mg}, 3 \mathrm{mg}, 10 \mathrm{mg}$ or $15 \mathrm{mg}$ or placebo for 8 weeks. A dose-dependent response was observed. The primary outcome (clinical response) was observed in $78 \%$ of patients receiving tofacitinib at a dose of $15 \mathrm{mg}$ compared with $42 \%$ of patients receiving placebo $(\mathrm{p}<0.001)$. Clinical remission (defined as a Mayo score $\leq 2$ with no subscore $>1$ ) occurred in $48 \%$ and $41 \%$ of patients receiving tofacitinib $10 \mathrm{mg}(\mathrm{p}<0.001)$ and $15 \mathrm{mg}(\mathrm{p}<0.001)$, respectively, compared with $10 \%$ of patients receiving placebo. ${ }^{23} \mathrm{~A}$ dose-dependent increase in both low-density and high-density lipoprotein cholesterol was observed, and neutropenia occurred in three patients. Overall, the adverse event rates were similar for tofacitinib and placebo. However, we must bear in mind that larger and longer studies using this molecule in rheumatoid arthritis have reported other dose-related side effects such as infections (including tuberculosis), increased lipid levels, anaemia, neutropenia, elevation of transaminases and possibly changes in renal function. ${ }^{24} 25$ Larger phase III studies (ClinicalTrials.gov NCT01465763, NCT01458951 and NCT01470612) involving tofacitinib are currently recruiting patients and will be helpful in defining the role of this oral drug in the treatment of UC.

\section{Interferon $\gamma$-inducible protein-10}

Interferon $\gamma$-inducible protein-10 (IP-10) is a chemokine that plays an important role in inflammatory cell migration and survival of epithelial cells, the expression of which is elevated in the colon and plasma of patients with UC. In a recent 8 -week phase II randomised controlled proof-of-concept study in 109 patients with moderately to severely active UC, BMS-936557, a monoclonal antibody against IP-10, did not significantly improve rates of clinical response, clinical remission or mucosal healing compared with placebo. ${ }^{26}$ However, in patients who developed high steady state concentrations of BMS-936557 there was a significantly increased clinical response rate compared with placebo $(87.5 \%$ for the highest tertile vs $37.0 \%$; $\mathrm{p}<0.001)$.

\section{INNOVATIVE THERAPEUTIC TARGETS IN UC Reinforcing the mucosal barrier}

The normal mucosal barrier is composed of a mucus layer, epithelial cells (including goblet cells and Paneth cells) and non-epithelial cells and intercellular and tight junctions, all intrinsically interconnected and working together to synthesise antimicrobial peptides and prevent luminal antigens and pathogenic organisms from invading the underlying lymphoid tissue. Disturbance of this barrier integrity is undoubtedly a key step in the pathogenesis of UC. Barrier dysfunction enables the influx of luminal antigens, which will continuously trigger immune cells in the lamina propria resulting in chronic inflammation. Restoring altered barrier function is therefore a strong potential therapeutic target in UC (figure 1).

\section{Phosphatidylcholine (PC)}

The mucus layer coating the gastrointestinal (GI) tract is predominantly composed of water, glycoproteins, lipids, other proteins and nucleic acids. ${ }^{27}$ Phospholipids, although minor constituents of the GI mucus, are indispensable for the maintenance of an intact barrier function where they play a role in establishing the hydrophobic surface by virtue of their amphipathic nature. ${ }^{28}$ Phosphatidylcholine (PC), the major mucus phospholipid, has been found to be substantially reduced in the mucus of patients with UC compared with patients with Crohn's disease (CD) and healthy controls, independent of the state of inflammation. ${ }^{27} 29$ A lack of PC could result in a reduction in surface hydrophobicity, enabling the invasion of luminal noxious agents. Furthermore, by virtue of being integrated in the plasma membranes of enterocytes, PC participates in various mucosal pathways including tumour necrosis factor $\alpha$ (TNF $\alpha)$ signalling, activation of NF- $\kappa \mathrm{B}$ cytokine expression and mitogen-activated protein kinase. $^{28} 30$ Therefore, it has been hypothesised that PC reconstitution in the colonic mucus of patients with UC could help to restore the structure and density of the mucus, improving the barrier function and preventing inflammation in UC. ${ }^{31}$ The results of phase II preliminary trials were very encouraging. Using a retarded-release preparation of $\mathrm{PC}$ in a randomised 

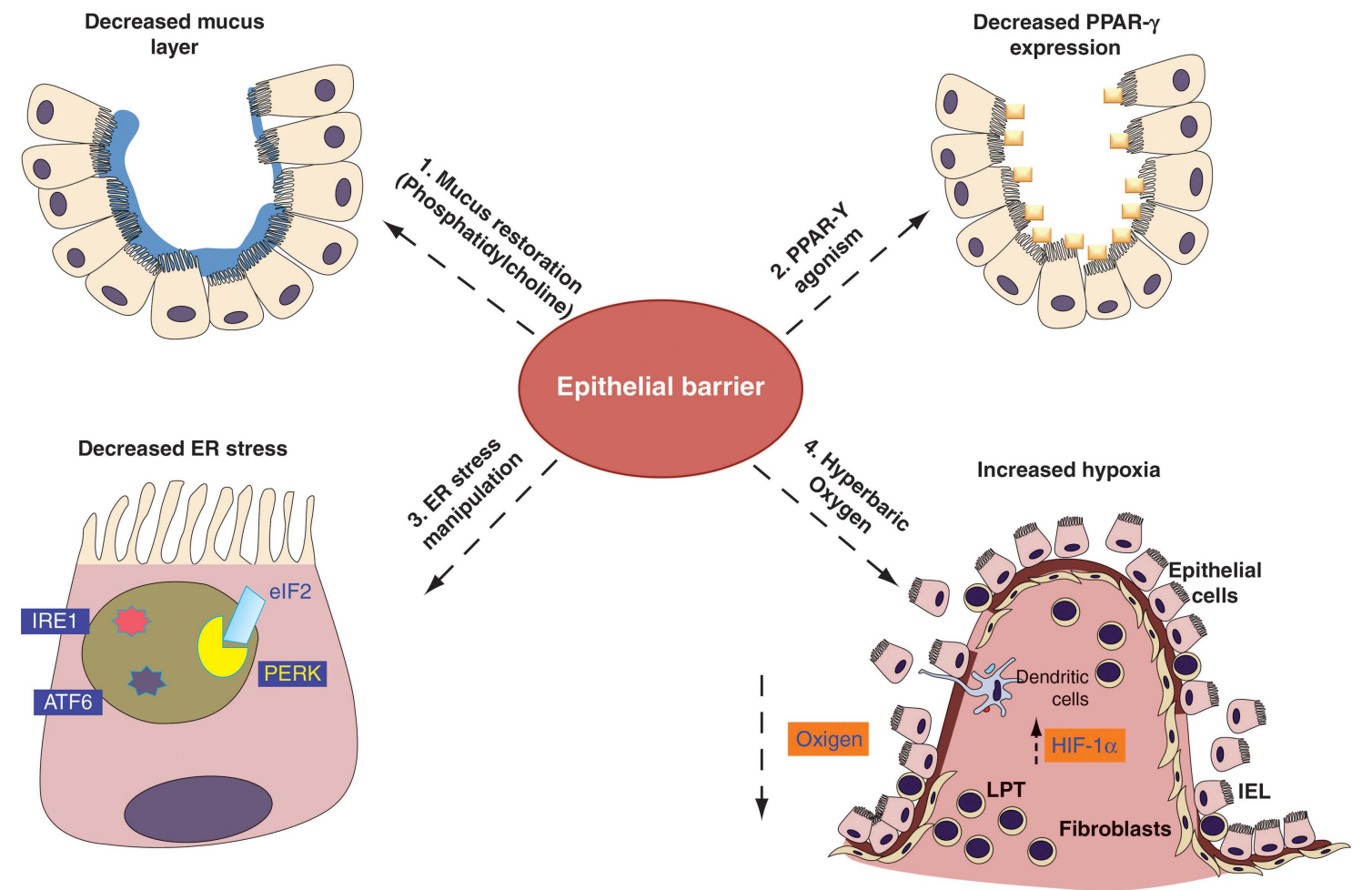

Figure 1 Potential new therapeutic avenues for ulcerative colitis through epithelial barrier restoration by (1) restoring the mucus layer; (2) stimulating peroxisome proliferator-activated receptor gamma (PPAR $\gamma$ ); (3) manipulating endothelium reticulum (ER) stress signalling pathways; and (4) modifying oxygen-related pathways such as hypoxia-inducible factor $1 \alpha$ (HIF-1 $\alpha$ ), thereby increasing oxygen tension.

double-blind placebo-controlled trial, $90 \%$ of patients either reached clinical remission (defined as a clinical activity index $(\mathrm{CAI}) \leq 3$ ) or significantly improved by $>50 \%$ compared with $10 \%$ in the placebo group. ${ }^{31}$ In a more difficult to treat patient population of steroid-refractory UC, steroid withdrawal with concomitant achievement of a CAI index of $\leq 3$ or CAI improvement of $>50 \%$ was achieved in $50 \%(15 / 30)$ of the patients treated with PC compared with $10 \%(3 / 30)$ in the placebo group. ${ }^{32}$ Patients participating in the abovementioned trials were offered an open-label follow-up treatment after completion of each of the trials. After a mean follow-up time of 26 months, continuous remission was maintained in $33 \%$ of the PC-treated patients versus $10 \%$ of the controls $(p=0.004) .{ }^{33}$ Finally, the results of a phase IIb placebo-controlled dose-finding study with an optimised highly enriched PC preparation (LT-02; $0.8 \mathrm{~g}, 1.6 \mathrm{~g}$ and $3.2 \mathrm{~g}$ ) in 156 patients with mesalazine-refractory UC were recently presented. Remission rates doubled in the highest dose group compared with placebo $(31.4 \%$ vs $15 \%)$ and an overall improvement in endoscopic disease activity measured by mucosal healing, as well as an earlier time to symptom resolution, was found in patients receiving LT-02 treatment. ${ }^{34} 35$

In summary, PC appears to be a novel therapeutic approach capable of inducing remission in patients with moderate UC without the substantial adverse effects seen with steroid or immunosuppressive therapy. Larger studies to confirm its shortterm benefits and its ability to maintain remission are eagerly awaited.

\section{Peroxisome proliferator-activated receptor gamma agonists}

Peroxisome proliferator-activated receptor gamma (PPAR $\gamma)$ is a nuclear receptor originally identified for its role in controlling the expression of a large number of regulatory genes involved in lipid metabolism, adipocyte differentiation and insulin sensitisation. More recently, high PPAR $\gamma$ expression has been reported in the gut, particularly in colonic epithelial cells where microorganisms such as bacteria and yeast are able to increase its expression and/or activation. ${ }^{36}$ PPAR $\gamma$ expression is impaired in colonic epithelial cells of patients with UC, both in diseased and healthy mucosa, and negatively correlated with the severity of endoscopic disease activity. ${ }^{36} 37$

Thiazolidinediones (TZDs) are PPAR $\gamma$ synthetic agonists used as insulin-sensitising agents in the treatment of type 2 diabetes. TZDs have drawn the attention of gastroenterologists over several years for their prophylactic and therapeutic effects in different experimental models of acute and chronic colitis, reducing intestinal inflammation by $50-70 \%{ }^{38}$ Several clinical trials have investigated the efficacy of TZDs in patients with active UC. ${ }^{39-42}$ Lewis et al conducted a randomised double-blind 12-week placebo-controlled trial where the efficacy of rosiglitazone $4 \mathrm{mg}$ orally twice daily was compared with placebo in 105 patients with mild to moderate UC. ${ }^{40}$ After 12 weeks of treatment, $44 \%$ and $17 \%$ of rosiglitazone-treated patients versus $23 \%$ and $2 \%$ of placebo-treated patients achieved a clinical response $(p=0.04)$ and clinical remission $(p=0.01)$, respectively. In this trial serious adverse events were rare. However, these very encouraging results have been dampened by some safety issues associated with the TZDs, particularly rosiglitazone, which was found to be associated with increased risks of cardiovascular events. ${ }^{43} 44$

New hope came from the demonstration that 5-aminosalicylates are ligands for PPAR $\gamma$ (figure 2). ${ }^{45}$ This discovery formed the basis for the rational development of 5-aminosalicylic acid (5-ASA) analogues with a stronger affinity for PPAR $\gamma$ and fewer side effects. One of these analogues, the (R)-(-)-GED-0507-34, has demonstrated 100-150-fold higher anti-inflammatory activity than 5-ASA, giving promising results in both in vitro and in vivo 

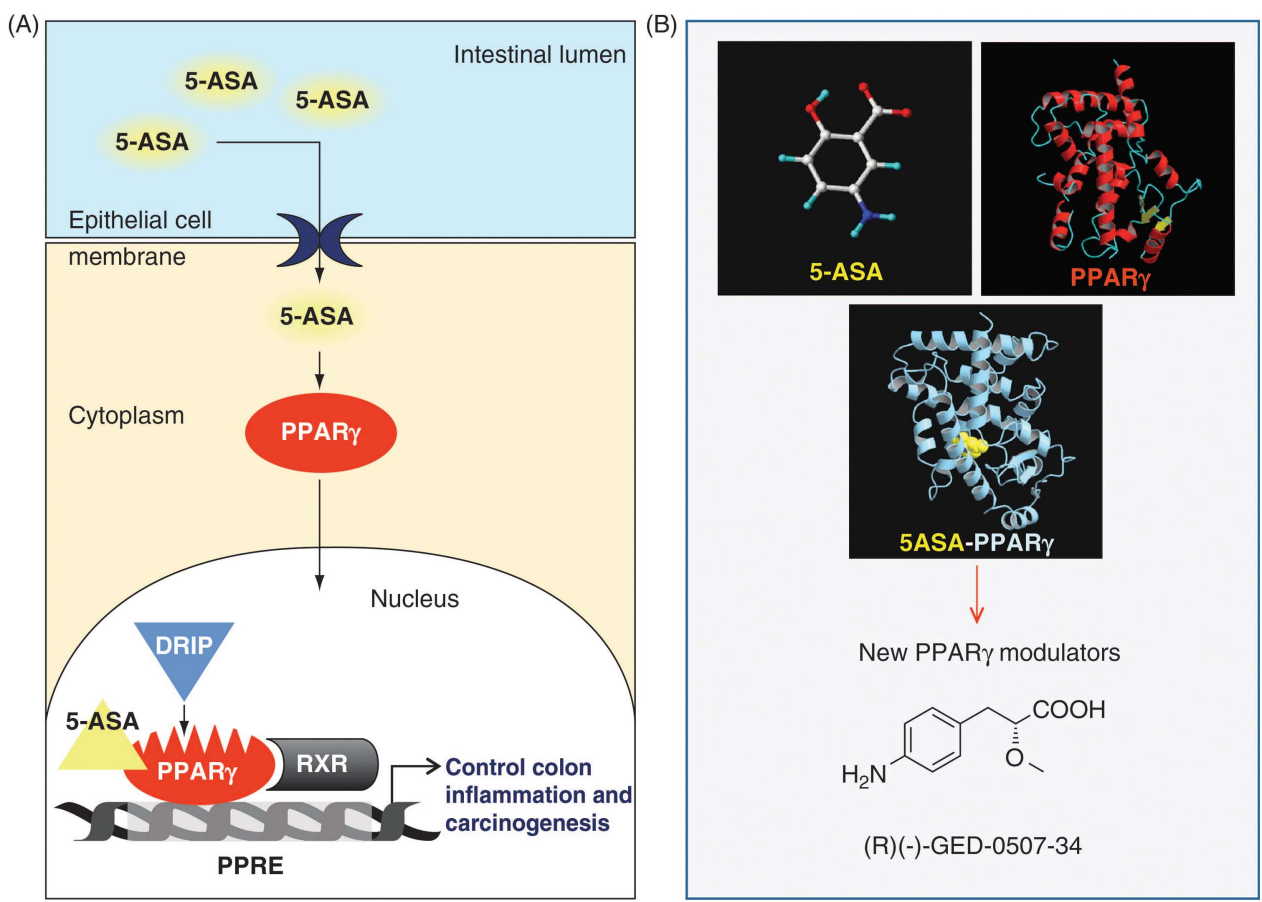

Figure 2 5-Aminosalicylic acid (5-ASA) is a ligand of peroxisome proliferator-activated receptor gamma (PPAR $\gamma$ ): a rationale to design new activators: (A) After oral administration, 5-ASA goes from the intestinal lumen to the epithelial cell cytoplasm through a cell membrane transporter. There, 5-ASA binds to PPAR $\gamma$ and induces its nuclear translocation. This binding promotes a PPAR $\gamma$ conformational change leading to the formation of a heterodimer between PPAR $\gamma$ and the retinoid $X$ receptor (RXR) that recruits the coactivator DRIP (the vitamin D receptor interacting protein). This complex then binds to a peroxisome proliferator response element (PPRE) on the DNA and induces the transcription of genes involved in the control of inflammation and carcinogenesis. (B) Based on the PPAR $\gamma$ tridimensional structure, the docking studies of 5-ASA within the ligand-binding domain of the receptor and the determination of the precise mechanisms of interaction between the two molecules is leading to the rational development of new PPAR $\gamma$ ligands with higher anti-inflammatory properties such as the (R)-(-)-GED-0507-34.

experimental models of colitis. This compound is currently in phase II clinical trials. ${ }^{46}$ These new molecules, coupled with an innovative system to deliver active substances to the colon, will make PPAR $\gamma$ modulators potential agents for induction and maintenance therapy in UC with limited side effects.

\section{Endoplasmic reticulum stress}

Within the colonic mucosa, goblet cells play a central role in epithelium protection. ${ }^{47}$ In agreement with the fact that an early decrease in mucosecretion is a histological pattern of UC, several recent experimental studies suggest that goblet cells are particularly sensitive to deregulation of a conserved cellular homeostatic mechanism-namely, endoplasmic reticulum (ER) stress. ${ }^{48}$ ER stress is a highly regulated physiological mechanism that allows the cell to adapt and survive through the activation of the three proximal sensors (IRE1, ATF6 and PERK) that sense the accumulation of misfolded proteins in response to environmental changes (infection, ischaemia, nutrients). ${ }^{49}$ Impairment of proper ER stress resolution induces proinflammatory responses and ER stress-dependent apoptosis. Different animal models have recently shown ways in which genetic impairment of ER stress resolution leads to spontaneous enteritis and colitis. 485051

A comprehensive analysis of ER stress responses in UC showed strong activation of IRE1 and ATF6 pathways (responsible for the induction of ER chaperones and proinflammatory pathways) associated with an unsuspected weak inhibition of PERK/eIF2 $\alpha$ pathway (figure 3). ${ }^{52}$ The drastic decrease in eIF $2 \alpha$ phosphorylation observed in the inactive mucosa from patients with UC was associated with an overexpression of GADD34, an effector of the negative feedback loop that dephosphorylates eIF $2 \alpha$. This defect in ER stress-dependent eIF2 $\alpha$ phosphorylation was thought to trigger reprogrammed translation and disruption of the proteostasis in non-inflamed colonic mucosa resulting in a weakened epithelial barrier. Pangenomic analysis of mRNA bound to polysomes isolated from controls and patients with UC revealed a subset of translationally regulated genes known to be involved in the pathogenesis of experimental colitis and UC, as well as selected genes that may play a crucial role in cell proliferation, ER stress, immune response and colorectal cancer. ${ }^{52}$ These alterations suggest primitive disturbances of ER stress susceptible to: (1) reprogramme protein synthesis in unaffected UC mucosa and (2) alter the capacity of colonic epithelium and, more particularly, goblet cells to cope with stress modulators derived from the local environment (bacteria, food digestion products, pollutants). This results in the activation of inflammatory signals relayed and perpetuated by immune cells.

Pharmacological restoration of the PERK/eIF2 pathway could represent a new therapeutic strategy in UC, switching the goal from mucosal to molecular healing of the mucosa.

\section{Improving hypoxia-related pathways}

There is a close relation between hypoxia, microvascular dysfunction and inflammation in IBD. ${ }^{53}$ Hypoxia is believed to activate NF- $\mathrm{KB}$ in intestinal epithelial cells. This leads to increased production of TNF $\alpha$ and expression of Toll-like receptors, which stimulates leucocyte recruitment, phagocytosis and adaptive immunity. ${ }^{53}$ Additionally, hypoxia-inducible factor 
Non-inflamed colonic mucosa



Figure 3 In healthy subjects the three branches of stress (IRE1, ATF6 and PERK) are coordinated and allow adaptation of the colonic mucosa to its environment. In patients with ulcerative colitis (UC), overactivation of IRE1 and ATF6 pathways is potentially responsible for a proinflammatory state of the mucosa. Hypophosporylation of elF2 alters the PERK pathway and the mucosal proteostasis. Regulators of the PERK/elF2 pathway are therefore promising candidates for UC control.

$1 \alpha$ (HIF-1 $\alpha$ ), a major oxygen homeostasis regulator that has been shown to be protective in experimental colitis, ${ }^{55}$ is upregulated under hypoxic conditions, activating genes essential to cellular adaptation to low oxygen conditions. Hence, handling of the oxygen sensing mechanisms and improvement of mechanisms that regulate mucosal oxygenation and hypoxia signalling may be potential therapeutic targets for the treatment of UC by improving the mucosal barrier.

Hyperbaric oxygen therapy (HBOT) involves the application of pressures $>1$ atmosphere absolute (ATA) to an environment of $100 \%$ oxygen. HBOT is used in many medical conditions due to its positive effects on wound healing. ${ }^{56} \mathrm{By}$ increasing the amount of dissolved oxygen carried in the plasma, HBOT increases neoangiogenesis in the early stage of wound healing, thus facilitating bacterial killing, resistance to infection, collagen synthesis and epithelialisation. ${ }^{55}$ Despite the theoretical potential of HBOT, only a few case reports or case series have reported on its use in UC. ${ }^{57-61}$ All treated patients were reported to be refractory to conventional therapies including immunosuppressors, and all patients had significant improvements with minimal adverse effects with HBOT delivered at 2.0 ATA. Unfortunately, all these studies were uncontrolled, with small numbers of patients and absence of strict endpoints. Larger controlled trials examining the effects of HBOT in patients with UC would be interesting to pursue.

\section{Harnessing the bugs}

The human intestinal microbiota is essential for host well-being due to their participation in several metabolic, nutritional and immune functions. ${ }^{62}$ Recent metagenomic advancements have provided new insights into the microbiota phylogenetic composition in health and in disease, as well its genetic and metabolic potential. $^{63}$ IBD involves a dysbiosis characterised by a decreased ratio of protective commensal bacteria from the phyla Firmicutes and Bacteroidetes (Clostridium XIVa and IV groups, Bacteroides, bifidobacteria) and a concomitant increase in detrimental bacteria from the phyla Proteobacteria and Actinobacteria. ${ }^{64}$ Recent analysis of the faecal microbiota of patients with UC in relapse and remission confirmed the reduction of bacterial diversity in these patients, mainly affecting members of the Clostridium cluster IV within the phylum Firmicutes. $^{65}$

While it is not clearly understood whether this dysbiosis is the cause or consequence of inflammation in IBD, it is believed that this imbalance between beneficial and pathogenic bacteria promotes perpetuation of inflammation. Therefore, manipulation of the dysbiosis may be an attractive way to prevent disease or induce its resolution.

\section{Faecal transplant}

An increasingly popular approach to reshape the gut microbiome is by means of faecal bacteriotherapy or faecal microbiome transplantation (FMT). This technique is supposed to restore the composition and function of the intestinal microbiota in diseased patients. It was first used in patients with Clostridum difficile infection when standard treatments had failed, ${ }^{66-68}$ but is increasingly being described in IBD. A systematic review of FMT in IBD has recently been published. ${ }^{69}$ Of the 26 patients with IBD receiving FMT for refractory disease, 18 were patients with UC. Of the treated patients with UC, 13 displayed symptom resolution or reduction. The number of infusions (mostly as an enema) varied between 1 and 70 . Although the available evidence is at best weak and limited, the rationale behind FTM makes it an interesting approach. However, we must bear in mind that there may be risks 
associated with this treatment as worsening of UC after faecal transplantation for Clostridium difficile has already been described, ${ }^{70}$ so patients should not be treated outside clinical trials. A better understanding of the microbiota changes that occur before and after FMT, its safety profile, a clarification of the best route of administration and of whether antibiotic preconditioning is necessary before FMT, and a perfection of the methods used to administer it in order to make it more acceptable by patients and their physicians is warranted. ${ }^{71}$ Four registered clinical trials (ClinicalTrials.gov NCT01545908, NCT01560819, NCT01650038 and NCT01650038) are currently recruiting patients for clinical studies using FMT in the treatment of UC or colonic CD. The results of these studies will hopefully shed some light on the efficacy and underlying mechanisms of FMT.

\section{Helminth therapy}

Epidemiological data suggest that the eradication of helminth in the developed world led to a rise in allergic and autoimmune diseases such as atopic dermatitis, multiple sclerosis, type 1 diabetes and IBD. Moreover, patients with immune-mediated disorders and exposure to parasites tend to have fewer exacerbations and improved symptoms. ${ }^{72} 73$ These data are further supported by the positive impact of helminth infections in laboratory models of colitis. ${ }^{74}$ Helminths or their soluble products, via their interaction with the host, activate several innate and adaptive immune regulatory pathways that may suppress inflammation. Exposure to helminths may alter the gut microbiome towards colonisation with more anti-inflammatory strains. ${ }^{75}$ They may modulate the function of dendritic cells. ${ }^{76}$ Helminthic exposure induces Th2 and regulatory T cell subsets within the intestinal mucosa and mesenteric lymph nodes, resulting in increased production of the anti-inflammatory cytokines IL-4, IL-5, IL-10 and transforming growth factor $\beta$ which activate macrophages ${ }^{77}$ and block effector $\mathrm{T}$ cell proliferation and secretion of proinflammatory cytokines IL-17 and interferon $\gamma$. $^{78}$

Clinical trials using helminths are being performed in several allergic and autoinflammatory diseases, including IBD, with encouraging results. ${ }^{79}$ In IBD, most of the trials use Trichuris suis ova (TSO) due to its safety profile. T suis has never been documented to cause human disease, multiply within the host or transmit from one human host to another (although this has been questioned). ${ }^{80}$ The very first openlabel trial of TSO in IBD was conducted in 2003 in a restricted number of $\mathrm{CD}$ and UC patients. ${ }^{81}$ Four patients with $\mathrm{CD}$ and three with UC were given one single dose of 2500 live TSO. Six of the seven patients achieved remission (according to the IBD Quality of Life Index), with no adverse effects. Only one of the completed TSO trials has been conducted in patients with UC alone. ${ }^{82}$ This was a randomised controlled double-blind trial in 54 patients with active UC who received either 2500 TSO or placebo every 2 weeks for 3 months. After 12 weeks of treatment, $43.4 \%$ of the patients given TSO improved compared with $16.7 \%$ of those given placebo $(p<0.04) .{ }^{82}$ No side effects were reported. A 24-week randomised double-blind placebo-controlled crossover study of TSO in patients with active UC is currently recruiting patients. Its main goal is to further clarify and characterise the mechanisms (mucus composition, change in effector lymphocyte populations, bacterial composition) triggered in response to the ingestion of TSO (ClinicalTrials.gov NCT01433471).
Genetically modified organisms as drug delivery systems Transgenic bacteria expressing interleukin-10

Advances in biotechnology have made possible the design of a new generation of mucosal delivery systems. Among these are genetically modified organisms such as bacterial or viral vector systems. ${ }^{83} 84$ These have proved to be effective and safe, but they raise concerns about survival and propagation in the environment.

The food-grade bacterium Lactococcus lactis is a good example of such a delivery vector for therapeutic proteins at mucosal sites. ${ }^{85} 86$ IL-10 has been shown to be a key cytokine in IBD, which led to the development of recombinant human IL-10 for subcutaneous administration. Unfortunately, IL-10 treatment was not as effective as expected in clinical trials, possibly because of the method of drug delivery. ${ }^{87}$ Using $L$ lactis-secreting murine IL-10 (mIL-10), investigators demonstrated that it was possible to reduce inflammatory symptoms in two murine colitis models. ${ }^{88}$ Furthermore, these investigators were able to modify this strain in order to make it biologically contained, thus overcoming safety issues. In a phase I trial, this approach was used to treat 10 patients with CD and was shown to be safe and effective in reducing disease activity. ${ }^{86}$

\section{Bacteria enhancing expression of elafin}

Elafin is a natural inhibitor of the proteases neutrophil elastase, proteinase- 3 and endogenous vascular elastase, ${ }^{89}$ enzymes produced by a variety of phagocytic inflammatory cells to degrade ingested pathogens and help cell motility through the extracellular matrix. Elafin is secreted by cells local to the site of inflammation in response to IL- $1, \mathrm{TNF} \alpha$, defensins, neutrophil elastase and lipopolysaccharide. ${ }^{90}$ It is expressed in several mucosal sites including the healthy intestinal epithelium. ${ }^{91}$ Besides its antiprotease properties, elafin has 'defensin-like' antimicrobial activity and anti-inflammatory properties promoting tissue remodelling and wound healing. ${ }^{92} 93$

Colonic tissues of patients with IBD have been reported to have increased proteolytic activity ${ }^{94}$ and decreased elafin mRNA expression. ${ }^{95}$ This suggests that the increase in elastolytic activity in the colon of patients with IBD correlates with a reduction in the expression of the endogenous protease inhibitor. Furthermore, elafin has been shown to prevent intestinal inflammation in mouse models of colitis, implying that delivery of elafin to the site of inflammation could naturally protect against IBD. ${ }^{96}$ However, to be delivered efficiently and safely, elafin would have to be delivered locally and progressively released in small amounts at the site of inflammation. An ingenious way for doing this has recently been developed. ${ }^{95}$ Investigators manipulated non-pathogenic lactic acid bacteria ( $L$ lactis and $L$ casei) normally present in dairy food, and introduced the human Elafin gene so that they would produce human elafin once at the site of inflammation. They showed that oral treatment with Elafin-expressing foodgrade bacteria downregulated inflammation both in acute and chronic mouse models of colonic inflammation. Furthermore, in cultures of human intestinal epithelial cells stimulated by an inflammatory milieu and treated with lactic acid bacilli secreting Elafin, the inflamed epithelium was protected from increased intestinal permeability and from the release of proinflammatory cytokines and chemokines. These results suggest that there may be a role for the clinical application of Elafin delivered by probiotic bacteria in treating IBD. 


\section{INNOVATIVE WAYS FOR DRUG DISCOVERY Novel plant-derived drugs}

Characterisation of new drug targets through clinical plantbased research is an evolving field in many areas such as cancer (eg, taxoids and camptothecins), infectious diseases, pain and inflammation. ${ }^{97-99}$

Andrographis paniculata is a member of the plant family Acanthaceae used in ayurvedic medicine and Chinese traditional medicine. Its extract (HMPL-004) has potent anti-inflammatory properties by inhibiting NF- $\mathrm{BB}$ activity, and its use is being explored in various medical conditions. In experimental colitis, HMPL-004 has been shown to affect $\mathrm{T}$ cell proliferation and differentiation and Th1/Th17 responses. ${ }^{100}$ Its clinical use has been already explored in phase II trials in UC. In a first trial, patients with mild to moderate UC were randomised to receive either $1200 \mathrm{mg}$ per day HMPL-004 or $4500 \mathrm{mg}$ mesalazine. By week 8 the rates of clinical and endoscopic response and remission were similar in both treatment groups, suggesting that HMPL-004 could be an alternative to mesalazine as an induction therapy. In a more recent trial, $1200 \mathrm{mg}$ or $1800 \mathrm{mg}$ daily of A paniculata extract were compared with placebo for 8 weeks for the induction of a clinical response in mild to moderate UC. ${ }^{101}$ Although there was no difference between the lower dose of the plant extract and placebo, $60 \%$ of patients receiving A paniculata $1800 \mathrm{mg}$ daily achieved a clinical response compared with $40 \%$ receiving placebo $(p=0.018)$. No difference in the rate of adverse events between the groups was observed, with the exception of rash which was higher in the group treated with A paniculata extract. ${ }^{101}$

\section{Computational drug repositioning (ex topiramate)}

Drug repositioning, repurposing or reprofiling involves the exploration of drugs that have already been approved for treatment of other diseases. It has the inherent advantages of being a less expensive and time-consuming process for drug development and is a strategy that is therefore becoming increasingly popular. ${ }^{102}$ Drug repositioning normally involves computational approaches, where public gene expression signatures known to be associated with a disease are screened against libraries of drugs with biological targets of interest. ${ }^{103}$ Topiramate, an antiepileptic drug, is an example of such drug repositioning in IBD. ${ }^{104}$ Using a computational approach where gene expression signatures of IBD derived from public microarray data were evaluated and run against a compendium of gene expression signatures of 164 drugs, Dudley et al found that topiramate presented a high therapeutic score prediction for use in IBD. Based on this finding, the authors then pursued a set of in vivo studies using the anticonvulsant drug in mice models of trinitrobenzene sulfonic acid (TNBS) colitis, demonstrating a reduction in clinical symptoms and in gross and microscopic pathological inflammation and therefore corroborating the results found in silico. ${ }^{104}$ Further clinical investigation of the use of topiramate for treating IBD in human subjects could be beneficial. It is likely that, with current in silico technologies and with the increasingly availability of public databases on the structures and biological activities of drugs, new opportunities for other drug repurposing in IBD will emerge.

\section{Nanotechnologies}

Nanomedicine is an emerging discipline that brings together nanotechnology and medicine. It refers to the utilisation of materials and devices at the nanometer scale in disease diagnosis, treatment and prevention, and it has the potential to turn molecular discoveries arising from systems biology into real benefits for patients. ${ }^{105} 106$ Nanomedicine will theoretically allow the accurate delivery of drugs to the sites of inflammation, therefore targeting their action and minimising their side effects. ${ }^{107}$

An example of this kind of nanotherapy is gene silencing via orally delivered small interfering RNAs (siRNAs). Using an oral nanoparticle capable of localising and delivering an siRNA directed against $\mathrm{TNF} \alpha$ to sites of intestinal inflammation, investigators effectively decreased the levels of TNF $\alpha$ mRNA levels in a dextran sulfate sodium (DSS)-induced mouse model of UC. ${ }^{108}$ Another illustration of the potential of these therapies includes the nanodelivery of IL-10-producing plasmid to the inflamed mucosa of IBD. ${ }^{109}$ In a TNBS murine model of intestinal inflammation, an oral system of nanoparticles-in-microsphere was formulated with murine IL-10-expressing plasmid DNA. Upon oral administration, IL-10 expression was enhanced in the large intestine leading to the suppression of proinflammatory cytokines. ${ }^{109}$

Although nanomedicine is still in its first steps, the results of these very preliminary studies provide evidence and potential utility for oral gene therapy in IBD. ${ }^{107}$

\section{FUTURE AVENUES FOR TRANSLATIONAL RESEARCH}

There are many clinical and epidemiological questions related to disease development and/or clinical evolution that remain to be answered. ${ }^{110}$ Yet, understanding some of the commonly observed clinical features of UC, such as the protective effect of tobacco or the mild phenotype presented by patients who have also been diagnosed with primary sclerosing cholangitis (PSC), could potentially improve our knowledge of the pathophysiology of the disease and lead to new avenues of research.

\section{Proximal extension of disease}

In contrast to $\mathrm{CD}$ where disease location is fairly stable, UC is a dynamic disease with the extent of colorectal inflammation changing over time in up to $50 \%$ of patients. ${ }^{13}$ Proximal extension of colorectal inflammation suggests a generalised susceptibility of the colonic mucosa to disease trigger factors. As discussed above, recent data show that the unaffected mucosa of patients with UC displays an inappropriate unfolded protein response compared with controls. ${ }^{52}$ Additionally, abnormal microRNA expression profiles have been demonstrated in the normal mucosa of patients with UC. ${ }^{111}$ These results show that, even in the normal appearing/non-inflamed mucosa of patients with UC, there are molecular differences harbouring a dormant inflammatory process which could have a crucial role interacting with environmental factors or other triggers of inflammation. The prospective identification of biological markers in the normal-appearing mucosa of patients that ultimately progress to more extensive colitis may lead to the development of new diagnostic tools to identify patients at risk of disease extension who could benefit from more aggressive therapeutic approaches.

\section{PSC-UC as a unique phenotype}

Patients with PSC-IBD typically have mildly symptomatic or even asymptomatic extensive colitis with prolonged remissions and a quiescent course of their colonic disease. ${ }^{112}{ }^{113}$ Furthermore, recent data suggest that there is an inverse relationship between the severity of the liver disease and of the UC, ${ }^{114-117}$ suggesting an intriguing cross-talk between the liver and the gut.

It has been shown that producing experimental hepatitis in mice models of colitis protects them from developing colitis. This is mediated by the influx of invariant natural killer $\mathrm{T}$ (iNKT) cells from the liver to the gut and mesenteric lymph 
nodes where they have anti-inflammatory functions and locally enhance the expression of IL-10. ${ }^{118}$ Confirmation of these results in humans could pave the way for new cell therapeutic strategies using NKT cells in IBD.

Faecal secondary bile acid (BA) rates are significantly lower in active IBD, possibly due to dysbiosis with a decrease in bacteria bearing bile salt hydrolase activities. ${ }^{119}$ Secondary BAs have anti-inflammatory properties due to their activation of $G$ protein-coupled specific membrane receptor TGR5, which inhibits the secretion of TNF $\alpha$, IL- $1 \beta$ and IL- 6 in macrophages. ${ }^{119}$ PSC is characterised by defective hepatic BA excretion that results in systemic BA accumulation as the disease progresses. This results in the activation of anticholestatic responses to provide alternative excretory routes and thus prevent accumulation of toxic components. ${ }^{120}$ At the intestinal level, the ileal expression of the apical bile salt transporter that permits intracellular absorption of BA is downregulated during obstructive cholestasis. $^{121} 122$ This could hypothetically lead to a relative increase of BAs entering the proximal colon in patients with PSC-UC where they would be converted from primary into secondary BAs.

BA homeostasis is tightly regulated by the activation of Farnesoid X Receptor (FXR) that is expressed at high levels in the liver and intestine. ${ }^{123}$ Recently, the BA-FXR axis has been implicated in intestinal barrier function. ${ }^{124} 125$ Intestinal inflammation decreases FXR expression in a colitis mouse model and FXR knockout mice have been shown to be more susceptible to intestinal inflammation. ${ }^{126}{ }^{127}$ FXR activation has been shown to protect against intestinal inflammation in mice, possibly by counterregulating inflammatory cytokine expression in immune cells. $^{128}{ }^{129}$ FXR agonists may therefore be an interesting approach for treating UC.

\section{Why is smoking protective against UC?}

Smoking is the most robust environmental association with UC. UC is predominantly a disease of non-smokers and former smokers. ${ }^{130-132}$ On the other hand, resumption of smoking has been shown to induce remission, even in medically refractory disease. $^{133} 134$

Many mechanisms have been proposed to explain the influence of smoking on IBD and its opposite effects in UC and CD. Smoking may have a different effect on the colon than on the small bowel; it might produce alterations in gut permeability and motility, in microcirculation and blood flow, and in the mucus composition. Nicotine produces changes in cytokine levels and modifies eicosanoid-mediated inflammation, production of oxygen-free radicals and the release of endogenous glucocorticoids. ${ }^{131}$ Furthermore, smoking has been shown to induce an ER stress response by activating the PERK/eIF2 axis, a mechanism that could explain the protective role of tobacco. $^{52} 135$

There is recent evidence suggesting that cigarette smoke exposure protects mice from experimental colitis through the action of iNKT cells. Using an innovative inhalation exposure system (the InExpose exposure system; Scireq) that more accurately reproduces human smoking habits, investigators first showed that smoking exposure selectively improved DSS-induced colitis (but not indomethacin-induced ileitis) in wild-type mice leading to a significant decrease in colonic TNF, IFN $\gamma$ and IL-22 mRNA expression together with an increased expression of IL-10 mRNA and a marked recruitment of iNKT. $^{136}$ Furthermore, using two different strains of NKT-deficient mice, the same immunoregulation induced by smoking exposure was no longer observed. This demonstrated that (similar to PSC), iNKT cells are pivotal in the regulation of colonic inflammation and that targeting these cells may offer therapeutic benefits in UC.

\section{What makes the appendix (or rather its absence) so special in UC?}

Surgical removal of the appendix is negatively associated with the development of UC, especially if performed at a young age. ${ }^{137}$ Indeed, appendicectomy has already been suggested as a valid therapeutic strategy. ${ }^{138} 139$

It has been shown that the ratio between CD4 and CD8 T cells and the proportion of CD4CD69 (early activation antigen) $\mathrm{T}$ cells are significantly increased in the appendix of patients with UC. ${ }^{140}$ Furthermore, in a T cell receptor- $\alpha$ chain knockout mouse model of colitis, appendicectomy performed at a young age was protective against the development of colitis. ${ }^{141}$ A link has been observed between acute appendicitis and an imbalance between bacteria with inflammatory (Fusobacterium nucleatum/necrophorum) and anti-inflammatory properties (Faecalibacterium prausnitzii), ${ }^{142}$ suggesting local appendicular dysbiosis as a potential explanation. ${ }^{143}$ Together, these observations imply that the appendix is an immunologically active organ involved in antigen sampling and in the regulation of the host-microbiome response. A better understanding of the pathways involved in the protection that appendicectomy confers against UC development may be helpful. A randomised multicentre trial designed to prospectively study the effect of laparoscopic appendicectomy on the clinical course of UC (the ACCURE trial) is currently ongoing and is likely to shed some light on this topic.

\section{Is it in the food?}

Changes in diet are a good mirror of the profound alterations in lifestyle that developing and industrialising societies face, leading many to look at diet as one of the environmental factors involved in IBD. In a recent French study, 67 581women were surveyed with self-administered questionnaires and their dietary habits were recorded at baseline and requestioned every 24 months. Among the participants, 77 incident IBD cases were diagnosed. Investigators found that a high total protein intake, specifically animal protein (meat or fish), was associated with a significantly increased risk of IBD. ${ }^{144}$

The mechanism explaining why animal proteins and/or fat would increase susceptibility to IBD is not clear, but it is likely that it could promote changes in bile salt composition and microbiome which in turn could be relevant to the initiation and maintenance of inflammation in genetically susceptible individuals. ${ }^{144}$ Investigators have shown that offering a high-fat diet and heme supplementation (normally present in high quantities in red meat) to a UC-like mouse model resulted in increased severity of colitis compared with mice fed with chow. ${ }^{145}$ In two mouse models of colitis, other investigators showed that introducing a diversified diet (in an attempt to replicate a more diverse and westernised type of diet) compared with a monotonous diet increased the severity of colitis. This was accompanied by microbiome changes-namely, a reduction in bacteria diversity. ${ }^{146}$ Devkota et al ${ }^{147}$ have shown that offering a diet rich in saturated fat to mice resulted in alterations in the pool of BAs which, in turn, stimulated the growth of sulfate-reducing bacteria that have been implicated in IBD. Further studies clarifying the impact of nutrients in the development and course of IBD may offer new insights into the early phases of disease development. 


\section{CONCLUSIONS}

UC is a serious medical condition with its own genetic, pathogenic and therapeutic identity. Despite all the recent advances, and even with our best available therapies, many patients remain symptomatic and present with a damaged colon with ulcerations, highlighting the need for new therapies. Many of the current strategies being developed in UC such as small molecules and new biological therapies focus on targeting the blockade or enhancement of soluble and cellular proteins and associated signalling mechanisms. However, thinking outside the box, looking at other components of UC pathophysiology and improving our understanding of some distinctive clinical and epidemiological features of disease may lead to the development of novel approaches and therapies.

While anticipating the arrival of novel and more effective medical therapy, we need to optimise the ones we currently have. This will involve being more stringent with our endpoints, introducing sufficiently potent drug regimens, optimising drug levels, intervening early before damage occurs and aiming at the sustained suppression of inflammation, with the ultimate goal of changing the course of disease.

Acknowledgements The authors thank Laurent Dubuquoy and Xavier Treton for their help with the figures.

Contributors JFC was responsible for the concept and design of the paper. All authors have contributed to the drafting, writing and critical revision of the manuscript for important intellectual content. All authors have agreed the final version to be published.

Competing interests None.

Provenance and peer review Commissioned; externally peer reviewed.

\section{REFERENCES}

1 Molodecky NA, Soon IS, Rabi DM, et al. Increasing incidence and prevalence of the inflammatory bowel diseases with time, based on systematic review. Gastroenterology 2012;142:46-54.e42.

2 Salkic NN, Pavlovic-Calic N, Gegic A, et al. Ulcerative colitis in the Tuzla region of Bosnia and Herzegovina between 1995 and 2006: epidemiological and clinical characteristics. Eur J Gastroenterol Hepatol 2010;22:346-53.

3 Yang SK, Hong WS, Min YI, et al. Incidence and prevalence of ulcerative colitis in the Songpa-Kangdong District, Seoul, Korea, 1986-1997. J Gastroenterol Hepatol 2000;15:1037-42.

4 Kitahora T, Utsunomiya T, Yokota A. Epidemiological study of ulcerative colitis in Japan: incidence and familial occurrence. The Epidemiology Group of the Research Committee of Inflammatory Bowel Disease in Japan. J Gastroenterol 1995;30 (Suppl 8):5-8.

5 Daiss W, Scheurlen M, Malchow $\mathrm{H}$. Epidemiology of inflammatory bowel disease in the county of Tubingen (West Germany). Scand J Gastroentero/ Supp/ 1989;170:39-43; discussion 50-5.

6 Lakatos L, Mester G, Erdelyi Z, et al. Striking elevation in incidence and prevalence of inflammatory bowel disease in a province of western Hungary between 1977-2001. World J Gastroenterol 2004;10:404-9.

7 Gunnarsson C, Chen J, Rizzo J, et al. Direct health care insurer and out-of-pocket expenditures of inflammatory bowel disease: evidence from a US National Survey. Dig Dis Sci 2012;57:3080-91.

8 Odes S. How expensive is inflammatory bowel disease? A critical analysis. World J Gastroenterol 2008; 14:6641-7.

9 Jess T, Frisch M, Simonsen J. Trends in overall and cause-specific mortality among patients with inflammatory bowel disease from 1982 to 2010. Clin Gastroenterol Hepatol 2013;11:43-8.

10 Kornbluth A, Sachar DB. Practice Parameters Committee of the American College of $\mathrm{G}$. Ulcerative colitis practice guidelines in adults: American College of Gastroenterology, Practice Parameters Committee. Am J Gastroenterol 2010;105:501-23; quiz 24

11 Dignass A, Lindsay JO, Sturm A, et al. Second European evidence-based consensus on the diagnosis and management of ulcerative colitis. Part 2: Current management. J Crohns Colitis 2012;6:991-1030.

12 Solberg IC, Lygren I, Jahnsen J, et al. Clinical course during the first 10 years of ulcerative colitis: results from a population-based inception cohort (IBSEN Study). Scand J Gastroenterol 2009:44:431-40.
13 Magro F, Rodrigues A, Vieira Al, et al. Review of the disease course among adult ulcerative colitis population-based longitudinal cohorts. Inflamm Bowel Dis 2012:18:573-83.

14 Kaplan GG, Seow CH, Ghosh S, et al. Decreasing colectomy rates for ulcerative colitis: a population-based time trend study. Am J Gastroenterol 2012;107:1879-87.

15 Danese $S$. New therapies for inflammatory bowel disease: from the bench to the bedside. Gut 2012;61:918-32.

16 Ghosh S, Panaccione R. Anti-adhesion molecule therapy for inflammatory bowel disease. Therap Adv Gastroenterol 2010;3:239-58.

17 MacDonald JK, McDonald JW. Natalizumab for induction of remission in Crohn's disease. Cochrane Database Syst Rev 2007;1:CD006097.

18 Parikh A, Wyant T, Clifford DB, et al. No increase in JC viremia, lymphocyte count, or circulating CD34+ hematopoietic progenitor cells after treatment with vedolizumab, a humanized monoclonal antibody to $\alpha 4 \beta 7$ integrin. Gastroenterology 2010;138:S145-6.

19 Feagan BG, Rutgeerts PJ, Sands BE, et al. Induction therapy for ulcerative colitis: results of GEMINI I, a randomized, placebo-controlled, double-blind, multicenter Phase 3 trial. Gastroenterology 2012;142:S160-1.

20 Sandborn W, Sands B, Rutgeerts P, et al. Sustained therapeutic benefit of vedolizumab throughout 1 year in ulcerative colitis in GEMINI I, a randomized, placebo-controlled, double-blind, multicenter trial. J Crohns Colitis 2013;7(Suppl 1):S138-\$9.

21 Feagan B, Sands B, Sankoh S, et al. Efficacy of vedolizumab in ulcerative colitis by prior treatment failure in GEMINI I, a randomised, placebo-controlled, double-blind, multi-centre trial. J Crohns Colitis 2013;7(Suppl 1):S216.

22 Ghoreschi $\mathrm{K}$, Jesson MI, Li X, et al. Modulation of innate and adaptive immune responses by tofacitinib (CP-690,550). J Immunol 2011;186:4234-43.

23 Sandborn WJ, Ghosh S, Panes J, et al. Tofacitinib, an oral Janus kinase inhibitor, in active ulcerative colitis. N Engl J Med 2012;367:616-24.

24 Maiga $M$, Lun $S$, Guo $H$, et al. Risk of tuberculosis reactivation with tofacitinib (CP-690550). J Infect Dis 2012;205:1705-8.

25 van Vollenhoven RF, Fleischmann $\mathrm{R}$, Cohen $\mathrm{S}$, et al. Tofacitinib or adalimumab versus placebo in rheumatoid arthritis. N Engl J Med 2012;367:508-19.

26 Mayer L, Sandborn WJ, Stepanov Y, et al. Anti-IP-10 antibody (BMS-936557) for ulcerative colitis: a phase II randomised study. Gut. Published Online First: 5 March 2013. doi: 10.1136/gutjnl-2012-303424

27 Braun A, Treede I, Gotthardt D, et al. Alterations of phospholipid concentration and species composition of the intestinal mucus barrier in ulcerative colitis: a clue to pathogenesis. Inflamm Bowel Dis 2009;15:1705-20.

28 Treede I, Braun A, Sparla R, et al. Anti-inflammatory effects of phosphatidylcholine. J Biol Chem 2007;282:27155-64.

29 Ehehalt R, Wagenblast J, Erben G, et al. Phosphatidylcholine and lysophosphatidylcholine in intestinal mucus of ulcerative colitis patients. A quantitative approach by nanoElectrospray-tandem mass spectrometry. Scand J Gastroenterol 2004;39:737-42.

30 Schneider H, Braun A, Fullekrug J, et al. Lipid based therapy for ulcerative colitis-modulation of intestinal mucus membrane phospholipids as a tool to influence inflammation. Int J Mol Sci 2010;11:4149-64.

31 Stremmel W, Merle U, Zahn A, et al. Retarded release phosphatidylcholine benefits patients with chronic active ulcerative colitis. Gut 2005;54:966-71.

32 Stremmel W, Ehehalt R, Autschbach F, et al. Phosphatidylcholine for steroid-refractory chronic ulcerative colitis: a randomized trial. Ann Intern Med 2007:147:603-10.

33 Karner M, Schmieg V, Hanemann A, et al. T1144 Results of a long-term follow-up treatment with delayed release phosphatidylcholine in chronic-active ulcerative colitis. Gastroenterology 2008;134:A-493.

34 Karner M, Kocjan A, Stein J, et al. 1157 Modified release phosphatidylcholine LT-02 in active ulcerative colitis - a randomized, placebo-controlled multicentre study. Gastroenterology 2012;142:S-211.

35 Karner M, Kocjan A, Stein J. First multicentre study of modified release phosphatidylcholine "LT-02" in active ulcerative colitis. Gut 2012;61(Suppl 3):A66.

36 Dubuquoy L, Jansson EA, Deeb $\mathrm{S}$, et al. Impaired expression of peroxisome proliferator-activated receptor gamma in ulcerative colitis. Gastroenterology 2003;124:1265-76.

37 Yamamoto-Furusho JK, Penaloza-Coronel A, Sanchez-Munoz F, et al. Peroxisome proliferator-activated receptor-gamma (PPAR-gamma) expression is downregulated in patients with active ulcerative colitis. Inflamm Bowel Dis 2011;17:680-1.

38 Dubuquoy L, Rousseaux C, Thuru X, et al. PPARgamma as a new therapeutic target in inflammatory bowel diseases. Gut 2006;55:1341-9.

39 Lewis JD, Lichtenstein GR, Stein RB, et al. An open-label trial of the PPAR-gamma ligand rosiglitazone for active ulcerative colitis. Am J Gastroenterol 2001;96:3323-8.

40 Lewis JD, Lichtenstein GR, Deren JJ, et al. Rosiglitazone for active ulcerative colitis: a randomized placebo-controlled trial. Gastroenterology 2008;134:688-95.

41 Liang $\mathrm{HL}$, Ouyang Q. A clinical trial of combined use of rosiglitazone and 5-aminosalicylate for ulcerative colitis. World J Gastroenterol 2008;14:114-19. 
42 Pedersen G, Brynskov J. Topical rosiglitazone treatment improves ulcerative colitis by restoring peroxisome proliferator-activated receptor-gamma activity. Am J Gastroenterol 2010;105:1595-603.

43 Rosen CJ. The rosiglitazone story-lessons from an FDA Advisory Committee meeting. N Engl J Med 2007:357:844-6.

44 Rosen CJ. Revisiting the rosiglitazone story-lessons learned. N Engl J Med 2010;363:803-6.

45 Rousseaux C, Lefebvre B, Dubuquoy L, et al. Intestinal antiinflammatory effect of 5 -aminosalicylic acid is dependent on peroxisome proliferator-activated receptor-gamma. J Exp Med 2005;201:1205-15.

46 Pirat C, Farce A, Lebegue $N$, et al. Targeting peroxisome proliferator-activated receptors (PPARs): development of modulators. J Med Chem 2012;55:4027-61.

47 van der Sluis M, Bouma J, Vincent $A$, et al. Combined defects in epithelial and immunoregulatory factors exacerbate the pathogenesis of inflammation: mucin 2-interleukin 10-deficient mice. Lab Invest 2008;88:634-42.

48 Heazlewood CK, Cook MC, Eri R, et al. Aberrant mucin assembly in mice causes endoplasmic reticulum stress and spontaneous inflammation resembling ulcerative colitis. PLoS Med 2008;5:e54

49 Ron $D$, Walter $P$. Signal integration in the endoplasmic reticulum unfolded protein response. Nat Rev Mol Cell Biol 2007;8:519-29.

50 Kaser $A$, Lee $A H$, Franke $A$, et al. XBP1 links ER stress to intestinal inflammation and confers genetic risk for human inflammatory bowel disease. Cell 2008:134:743-56.

51 Kaser A, Martinez-Naves E, Blumberg RS. Endoplasmic reticulum stress: implications for inflammatory bowel disease pathogenesis. Curr Opin Gastroenterol 2010;26:318-26.

52 Treton X, Pedruzzi E, Cazals-Hatem D, et al. Altered endoplasmic reticulum stress affects translation in inactive colon tissue from patients with ulcerative colitis Gastroenterology 2011;141:1024-35.

53 Eltzschig HK, Carmeliet P. Hypoxia and inflammation. N Engl J Med 2011;364:656-65

54 Chen LW, Egan L, Li ZW, et al. The two faces of IKK and NF-kappaB inhibition: prevention of systemic inflammation but increased local injury following intestinal ischemia-reperfusion. Nat Med 2003:9:575-81.

55 Karhausen J, Furuta GT, Tomaszewski JE, et al. Epithelial hypoxia-inducible factor-1 is protective in murine experimental colitis. J Clin Invest 2004; 114:1098-106.

56 Shah SA. Healing with oxygen: a history of hyperbaric medicine. Pharos Alpha Omega Alpha Honor Med Soc 2000;63:13-19.

57 Buchman AL, Fife C, Torres $C$, et al. Hyperbaric oxygen therapy for severe ulcerative colitis. J Clin Gastroenterol 2001:33:337-9.

58 Demirturk L, Ozel M, Yazgan $Y$, et al. Therapeutic efficacy of hyperbaric oxygenation in ulcerative colitis refractory to medical treatment. J Clin Gastroenterol 2002;35:286-7; author reply 287-8.

59 Gurbuz AK, Elbuken E, Yazgan Y, et al. A different therapeutic approach in patients with severe ulcerative colitis: hyperbaric oxygen treatment. South Med J 2003:96:632-3.

60 Karkumov M, Nikolov N, Georgiev L, et al. Hyperbaric oxygenation as a part of the treatment of chronic ulcerohemorrhagic colitis. Vutr Boles 1991;30:78-80.

61 Kuroki $\mathrm{K}$, Masuda $\mathrm{A}$, Uehara $\mathrm{H}$, et al. A new treatment for toxic megacolon. Lancet 1998;352:782.

62 Ottman N, Smidt H, de Vos WM, et al. The function of our microbiota: who is out there and what do they do? Front Cell Infect Microbiol 2012;2:104

63 Frank DN, Pace NR. Gastrointestinal microbiology enters the metagenomics era. Curr Opin Gastroenterol 2008;24:4-10.

64 Frank DN, St Amand AL, Feldman RA, et al. Molecular-phylogenetic characterization of microbial community imbalances in human inflammatory bowel diseases. Proc Natl Acad Sci USA 2007;104:13780-5.

65 Rajilic-Stojanovic MSF, Guarner F, de Vos WM. Phylogenetic analysis of dysbiosis in ulcerative colitis in relapse and remission. Inflamm Bowel Dis 2013;19:481-8.

66 Bakken JS, Borody T, Brandt LJ, et al. Treating Clostridium difficile infection with fecal microbiota transplantation. Clin Gastroenterol Hepatol 2011;9:1044-9.

67 Kelly CP. Fecal microbiota transplantation-an old therapy comes of age. $N$ Engl $\mathrm{J}$ Med 2013;368:474-5.

68 van Nood E, Vrieze A, Nieuwdorp M, et al. Duodenal infusion of donor feces for recurrent clostridium difficile. N Engl J Med 2013;368:407-15.

69 Anderson JL, Edney RJ, Whelan K. Systematic review: faecal microbiota transplantation in the management of inflammatory bowel disease. Aliment Pharmacol Ther 2012;36:503-16.

70 Watson JB, Habr F, Kelly C. Su1934 First reported complication of fecal microbiota transplant: ulcerative colitis flare after FMT for relapsing clostridium difficile infection. Gastroenterology 2012:142:S-540.

71 Kahn SA, Gorawara-Bhat R, Rubin DT. Fecal bacteriotherapy for ulcerative colitis: patients are ready, are we? Inflamm Bowel Dis 2012;18:676-84.

72 Correale J, Farez M. Association between parasite infection and immune responses in multiple sclerosis. Ann Neurol 2007:61:97-108

73 Summers RW, Elliott DE, Urban JF Jr, et al. Trichuris suis therapy in Crohn's disease. Gut 2005:54:87-90.
74 Motomura $Y$, Wang $H$, Deng $Y$, et al. Helminth antigen-based strategy to ameliorate inflammation in an experimental model of colitis. Clin Exp Immunol 2009:155:88-95.

75 Walk ST, Blum AM, Ewing SA, et al. Alteration of the murine gut microbiota during infection with the parasitic helminth Heligmosomoides polygyrus. Inflamm Bowel Dis 2010;16:1841-9.

76 Klaver EJ, Kuijk LM, Laan LC, et al. Trichuris suis-induced modulation of human dendritic cell function is glycan-mediated. Int J Parasitol 2013;43:191-200.

77 Smith $\mathrm{P}$, Mangan NE, Walsh CM, et al. Infection with a helminth parasite prevents experimental colitis via a macrophage-mediated mechanism. J Immunol 2007; 178:4557-66.

78 Elliott DE, Metwali A, Leung J, et al. Colonization with Heligmosomoides polygyrus suppresses mucosal IL-17 production. J Immunol 2008;181:2414-9.

79 Elliott DE, Weinstock JV. Helminthic therapy: using worms to treat immune-mediated disease. Adv Exp Med Biol 2009;666:157-66.

80 Van Kruiningen HJ, West AB. Potential danger in the medical use of Trichuris suis for the treatment of inflammatory bowel disease. Inflamm Bowel Dis 2005;11:515.

81 Summers RW, Elliott DE, Qadir K, et al. Trichuris suis seems to be safe and possibly effective in the treatment of inflammatory bowel disease. Am $\mathrm{J}$ Gastroenterol 2003;98:2034-41.

82 Summers RW, Elliott DE, Urban JF Jr, et al. Trichuris suis therapy for active ulcerative colitis: a randomized controlled trial. Gastroenterology 2005;128:825-32.

83 Daudel D, Weidinger G, Spreng $S$. Use of attenuated bacteria as delivery vectors for DNA vaccines. Expert Rev Vaccines 2007:6:97-110.

84 Yuvaraj S, Peppelenbosch MP, Bos NA. Transgenic probiotica as drug delivery systems: the golden bullet? Expert Opin Drug Deliv 2007:4:1-3.

85 Huyghebaert N, Vermeire A, Neirynck S, et al. Development of an enteric-coated formulation containing freeze-dried, viable recombinant Lactococcus lactis for the ileal mucosal delivery of human interleukin-10. Eur J Pharm Biopharm 2005;60:349-59.

86 Braat $\mathrm{H}$, Rottiers $\mathrm{P}$, Hommes DW, et al. A phase I trial with transgenic bacteria expressing interleukin-10 in Crohn's disease. Clin Gastroenterol Hepatol 2006:4:754-9.

87 Schreiber S, Fedorak RN, Nielsen $\mathrm{OH}$, et al. Safety and efficacy of recombinant human interleukin 10 in chronic active Crohn's disease. Crohn's Disease IL-10 Cooperative Study Group. Gastroenterology 2000;119:1461-72.

88 Steidler L, Neirynck S, Huyghebaert N, et al. Biological containment of genetically modified Lactococcus lactis for intestinal delivery of human interleukin 10. Nat Biotechnol 2003;21:785-9.

89 Moreau T, Baranger K, Dade S, et al. Multifaceted roles of human elafin and secretory leukocyte proteinase inhibitor (SLPI), two serine protease inhibitors of the chelonianin family. Biochimie 2008;90:284-95.

90 Sallenave JM, Shulmann J, Crossley J, et al. Regulation of secretory leukocyte proteinase inhibitor (SLPI) and elastase-specific inhibitor (ESI/elafin) in human airway epithelial cells by cytokines and neutrophilic enzymes. Am J Respir Cell Mol Biol 1994;11:733-41.

91 Suzuki Y, Furukawa M, Abe J, et al. Localization of porcine trappin-2 (SKALP) elafin) in trachea and large intestine by in situ hybridization and immunohistochemistry. Histochem Cell Biol 2000;114:15-20.

92 Shaw L, Wiedow O. Therapeutic potential of human elafin. Biochem Soc Trans 2011:39:1450-4.

93 Greenhill C. IBD: elafin-a potential IBD therapy. Nat Rev Gastroenterol Hepatol 2012;9:686.

94 Vergnolle N, Cellars L, Mencarelli A, et al. A role for proteinase-activated receptor-1 in inflammatory bowel diseases. J Clin Invest 2004;114:1444-56.

95 Motta JP, Bermudez-Humaran LG, Deraison C, et al. Food-grade bacteria expressing elafin protect against inflammation and restore colon homeostasis. Sci Transl Med 2012:4:158ra44.

96 Motta JÄ, Magne L, Descamps D, et al. Modifying the protease, antiprotease pattern by elafin overexpression protects mice from colitis. Gastroenterology 2011;140:1272-82.

97 Balunas MJ, Kinghorn AD. Drug discovery from medicinal plants. Life Sci 2005;78:431-41.

98 Rawat DS, Singh R. Plant-derived secondary metabolites as anticancer agents. Anticancer Agents Med Chem. Published Online First 7 February 2013. PMID: 23438829.

99 Ribeiro A, Ferraz-de-Paula V, Pinheiro ML, et al. Cannabidiol, a non-psychotropic plant-derived cannabinoid, decreases inflammation in a murine model of acute lung injury: role for the adenosine A2A receptor. Eur J Pharmacol 2012;678:78-85.

100 Michelsen KS, Wong MH, Ko B, et al. HMPL-004 (Andrographis paniculata extract) prevents development of murine colitis by inhibiting T-cell proliferation and TH1/ TH17 responses. Inflamm Bowel Dis 2013;19:151-64.

101 Sandborn WJ, Targan SR, Byers VS, et al. Andrographis paniculata extract (HMPL-004) for active ulcerative colitis. Am J Gastroenterol 2013;108:90-8.

102 O'Connor KA, Roth BL. Finding new tricks for old drugs: an efficient route for public-sector drug discovery. Nat Rev Drug Discov 2005;4:1005-14. 
103 Sirota M, Dudley JT, Kim J, et al. Discovery and preclinical validation of drug indications using compendia of public gene expression data. Sci Trans/ Med 2011:3:96ra77.

104 Dudley JT, Sirota M, Shenoy M, et al. Computational repositioning of the anticonvulsant topiramate for inflammatory bowel disease. Sci Trans/ Med 2011;3:96ra76

105 Boulaiz H, Alvarez PJ, Ramirez A, et al. Nanomedicine: application areas and development prospects. Int J Mol Sci 2011;12:3303-21.

106 Moghimi SM, Hunter AC, Murray JC. Nanomedicine: current status and future prospects. FASEB J 2005;19:311-30.

107 Pichai MV, Ferguson LR. Potential prospects of nanomedicine for targeted therapeutics in inflammatory bowel diseases. World I Gastroenterol 2012; 18:2895-901.

108 Wilson DS, Dalmasso G, Wang L, et al. Orally delivered thioketal nanoparticles loaded with TNF-alpha-siRNA target inflammation and inhibit gene expression in the intestines. Nat Mater 2010;9:923-8.

109 Bhavsar MD, Amiji MM. Oral IL-10 gene delivery in a microsphere-based formulation for local transfection and therapeutic efficacy in inflammatory bowel disease. Gene Ther 2008;15:1200-9.

110 Colombel JF, Watson AJ, Neurath MF. The 10 remaining mysteries of inflammatory bowel disease. Gut 2008:57:429-33.

111 Fasseu M, Treton X, Guichard C, et al. Identification of restricted subsets of mature microRNA abnormally expressed in inactive colonic mucosa of patients with inflammatory bowel disease. PLoS One 2010;5:e13160.

112 Loftus EV Jr, Harewood GC, Loftus CG, et al. PSC-IBD: a unique form of inflammatory bowel disease associated with primary sclerosing cholangitis. Gut 2005:54:91-6.

113 Lundqvist K, Broome U. Differences in colonic disease activity in patients with ulcerative colitis with and without primary sclerosing cholangitis: a case control study. Dis Colon Rectum 1997;40:451-6.

114 Marelli L, Xirouchakis E, Kalambokis G, et al. Does the severity of primary sclerosing cholangitis influence the clinical course of associated ulcerative colitis? Gut 2011;60:1224-8.

115 Navaneethan U, Venkatesh PG, Mukewar S, et al. Progressive primary sclerosing cholangitis requiring liver transplantation is associated with reduced need for colectomy in patients with ulcerative colitis. Clin Gastroenterol Hepatol 2012;10:540-6

116 Gelley F, Miheller P, Peter A, et al. Activity of ulcerative colitis before and after liver transplantation in primary sclerosing cholangitis: the Hungarian experience. Transplant Proc 2012;44:2164-5.

117 Moncrief KJ, Savu A, Ma MM, et al. The natural history of inflammatory bowel disease and primary sclerosing cholangitis after liver transplantation-a single-centre experience. Can J Gastroenterol 2010;24:40-6.

118 Chakass D, Hamdi H, Faveeuw C, et al. Early involvement of liver natural killer T cells in limiting colonic inflammation and application to disease treatment. Gastroenterology 2011;140:S-1.

119 Duboc H, Rajca S, Rainteau D, et al. Connecting dysbiosis, bile-acid dysmetabolism and gut inflammation in inflammatory bowel diseases. Gut 2013;62:531-9.

120 Maillette de Buy Wenniger L, Beuers U. Bile salts and cholestasis. Dig Liver Dis 2010:42:409-18.

121 Hruz P, Zimmermann C, Gutmann H, et al. Adaptive regulation of the ileal apical sodium dependent bile acid transporter (ASBT) in patients with obstructive cholestasis. Gut 2006;55:395-402.

122 Sauer $\mathrm{P}$, Stiehl A, Fitscher BA, et al. Downregulation of ileal bile acid absorption in bile-duct-ligated rats. J Hepatol 2000;33:2-8.

123 Chiang JY. Hepatocyte nuclear factor 4alpha regulation of bile acid and drug metabolism. Expert Opin Drug Metab Toxicol 2009;5:137-47.

124 Gadaleta RM, van Mil SW, Oldenburg B, et al. Bile acids and their nuclear receptor FXR: relevance for hepatobiliary and gastrointestinal disease. Biochim Biophys Acta 2010;1801:683-92.

125 Inagaki T, Moschetta $\mathrm{A}$, Lee $\mathrm{YK}$, et al. Regulation of antibacterial defense in the small intestine by the nuclear bile acid receptor. Proc Natl Acad Sci USA 2006; 103:3920-5.
126 Vavassori P, Mencarelli A, Renga B, et al. The bile acid receptor FXR is a modulator of intestinal innate immunity. J Immunol 2009;183:6251-61.

127 Gadaleta RM, van Erpecum KJ, Oldenburg B, et al. Farnesoid X receptor activation inhibits inflammation and preserves the intestinal barrier in inflammatory bowel disease. Gut 2011;60:463-72.

128 Renga B, Migliorati M, Mencarelli A, et al. Reciprocal regulation of the bile acid-activated receptor FXR and the interferon-gamma-STAT-1 pathway in macrophages. Biochim Biophys Acta 2009;1792:564-73.

129 Gadaleta RM, Oldenburg B, Willemsen EC, et al. Activation of bile salt nuclear receptor FXR is repressed by pro-inflammatory cytokines activating NF-kappaB signaling in the intestine. Biochim Biophys Acta 2011;1812:851-8.

130 Calkins BM. A meta-analysis of the role of smoking in inflammatory bowel disease. Dig Dis Sci 1989;34:1841-54.

131 Birrenbach T, Bocker U. Inflammatory bowel disease and smoking: a review of epidemiology, pathophysiology, and therapeutic implications. Inflamm Bowel Dis 2004;10:848-59.

132 Beaugerie L, Massot N, Carbonnel F, et al. Impact of cessation of smoking on the course of ulcerative colitis. Am J Gastroenterol 2001;96:2113-6.

133 Calabrese E, Yanai H, Shuster D, et al. Low-dose smoking resumption in ex-smokers with refractory ulcerative colitis. J Crohns Colitis 2012;6:756-62.

134 Cottone M, Georgios A, Sinagra E. Smoking therapy may be an extreme cure in exsmokers with steroid-dependent and resistant ulcerative colitis. Inflamm Bowel Dis 2011;17:2213.

135 Hengstermann A, Muller T. Endoplasmic reticulum stress induced by aqueous extracts of cigarette smoke in 3 T3 cells activates the unfolded-proteinresponse-dependent PERK pathway of cell survival. Free Radic Biol Med 2008:44:1097-107.

136 Montbarbon M, Pichavant M, Langlois A, et al. Tu1940 cigarette smoke improves selectively colon and not small bowel inflammation through NKT cell activation. Gastroenterology 2012;142:S-883.

137 Andersson RE, Olaison G, Tysk C, et al. Appendectomy and protection against ulcerative colitis. N Engl I Med 2001;344:808-14.

138 Bolin TD, Wong S, Crouch R, et al. Appendicectomy as a therapy for ulcerative proctitis. Am J Gastroenterol 2009;104:2476-82.

139 Bageacu S, Coatmeur O, Lemaitre JP, et al. Appendicectomy as a potential therapy for refractory ulcerative proctitis. Aliment Pharmacol Ther 2011;34:257-8.

140 Matsushita M, Takakuwa H, Matsubayashi Y, et al. Appendix is a priming site in the development of ulcerative colitis. World I Gastroenterol 2005;11:4869-74

141 Mizoguchi A, Mizoguchi E, Chiba C, et al. Role of appendix in the development of inflammatory bowel disease in TCR-alpha mutant mice. J Exp Med 1996:184:707-15.

142 Swidsinski A, Dorffel Y, Loening-Baucke V, et al. Acute appendicitis is characterised by local invasion with Fusobacterium nucleatum/necrophorum. Gut 2011;60:34-40

143 Roblin X, Neut C, Darfeuille-Michaud A, et al. Local appendiceal dysbiosis: the missing link between the appendix and ulcerative colitis? Gut 2012:61:635-6.

144 Jantchou P, Morois S, Clavel-Chapelon F, et al. Animal protein intake and risk of inflammatory bowel disease: the E3N prospective study. Am J Gastroenterol 2010;105:2195-201.

145 van der Logt EM, Blokzijl T, van der Meer R, et al. Westernized high-fat diet accelerates weight loss in dextran sulfate sodium-induced colitis in mice, which is further aggravated by supplementation of heme. J Nutr Biochem. pii: S0955-2863 (12)00241-0.

146 Nagy-Szakal D, Mir SA, Ross MC, et al. Monotonous diets protect against acute colitis in mice: epidemiologic and therapeutic implications. J Pediatr Gastroenterol Nutr. Published Online First: 18 October 2012. doi:10.1097/MPG. Ob013e3182769748

147 Devkota S, Wang Y, Musch MW, et al. Dietary-fat-induced taurocholic acid promotes pathobiont expansion and colitis in II10-/- mice. Nature 2012:487:104-8. 